\title{
Surge - A Fast Open-Source Chemical Graph Generator
}

\author{
Brendan D. McKay ${ }^{1 *}$, Mehmet Aziz Yirik ${ }^{2}$ and Christoph Steinbeck ${ }^{2 *}$ \\ ${ }^{1}$ School of Computing, Australian National University, ACT 2601, Australia \\ ${ }^{2}$ Institute of Inorganic and Analytical Chemistry, Friedrich-Schiller-University, Lessingstr. 8, \\ 07743 Jena, Germany
}

Corresponding author email: brendan.mckay@anu.edu.au, christoph.steinbeck@uni-jena.de

\section{Abstract}

Chemical structure generators are used in cheminformatics to produce or enumerate virtual molecules based on a set of boundary conditions. The result can then be tested for properties of interest, such as adherence to measured data or for their suitability as drugs. The starting point can be a potentially fuzzy set of fragments or a molecular formula. In the latter case, the generator produces the set of constitutional isomers of the given input formula. Here we present the novel constitutional isomer generator surge based on the canonical generation path method. Surge uses the nauty package to compute automorphism groups of graphs. We outline the working principles of surge and present benchmarking results which show that surge is currently the fastest structure generator. Surge is available under a liberal open-source license.

\section{Introduction}

Chemical structure generators enumerate or generate molecular graphs of organic or bioorganic molecules. They are an integral part of systems for computer-assisted structure elucidation (CASE) [1] and can be used to create molecular libraries for virtual screening [2], [3] or enumerate chemical spaces in general [4]. The history of chemical graph generators goes back at least to the 1960s DENDRAL project which was aimed at the CASE of organic molecules based on mass spectrometric data [5]. DENDRAL was developed for NASA's Mariner program to search for life on Mars [5] [6]. Its structure generator used substructures as building blocks and was able to deal with overlapping substructures. In the early history of the structure generators, ASSEMBLE was another building block based structure generator [7]. In the field, there is a family of generators based on mathematical theorems such as algorithmic group theory [8] and combinatorics [9]. Besides DENDRAL, MASS [10] was also another good example for the applications of mathematical theorems in structure generation. It was a tool for 
the mathematical analysis of molecular structures. SMOG [11] was the successor of the MASS algorithm.

Many works followed but few examples of practical usability are available even today [12]. Among the currently available structure generators, such as DENDRAL, ASSEMBLE, SMOG, COCON [13] and LSD [14], MOLGEN [15] constituted the state-of-the-art for decades in terms of speed, completeness and reliability. The first version of MOLGEN was based on the strategy of DENDRAL software and developed to overcome the limitations of DENDRAL [16]. The software is based on the orderly graph generation method [17]. Although MOLGEN is the de facto gold standard in the field, it has the downside of being closed-source software. The algorithm cannot be further developed or modified by scientists based on their interests. The most efficient and fast open-source chemical graph generator was MAYGEN [18] based on the orderly generation method. However, MAYGEN is approximately 3 times slower than MOLGEN. The state of the art of large scale structure generation was recently set by the lab of Jean-Louis Reymond [19] in developing an in-house solution for a nauty-based structure generator, which enabled them to produce the numeration of 166 billion organic small molecules in the chemical universe database GDB-17. To the best of our knowledge, this in-house generator was not released as open-source or otherwise.

Thus, there is still the need for an efficient open-source chemical graph generator. In [18] we expressed the hope to "trigger a surge in the development of improved and faster" structure generators. Here we present the novel structure generator surge, based on the principle of the canonical generation path method. Surge is open-source and outperforms MOLGEN 5.0 by orders of magnitude in speed. Furthermore, surge is easily extensible with more features and adaptable to further application.

\section{Methods}

\section{Data}

We assembled a list of molecular formulae for benchmarking surge against MOLGEN 5.0 in Table 1-2. These formulae were taken from the natural products database COCONUT [20]. The size of these molecular formulae varies and is enough to challenge even the best constitutional isomer generators available (see results section).

\section{Algorithm and mathematical background}

Surge is based on the nauty [21] package for computing automorphism groups of graphs as well as canonical labels. Like nauty, surge is written in a portable subset of $\mathrm{C}$ and runs on a considerable number of different systems.

Surge is an integration of three existing tools from the nauty suite [22]: a) geng generates simple graphs based on certain boundary conditions, b) vcolg colors vertices in the output of geng and c) multig inserts multi-edges in the output of the first two tools (Figure 1). 


\begin{tabular}{|c|c|c|}
\hline GENG & VCOLG & MULTIG \\
\hline
\end{tabular}

Figure 1: An example case for the combination of geng, vcolg and multig functions for the furan molecule, $\mathrm{C}_{4} \mathrm{H}_{4} \mathrm{O}$. First the simple graph is constructed. The nodes are coloured as, black for carbons and red for the oxygen. In multig, the edge multiplicities are optionally increased to create multiple bonds.

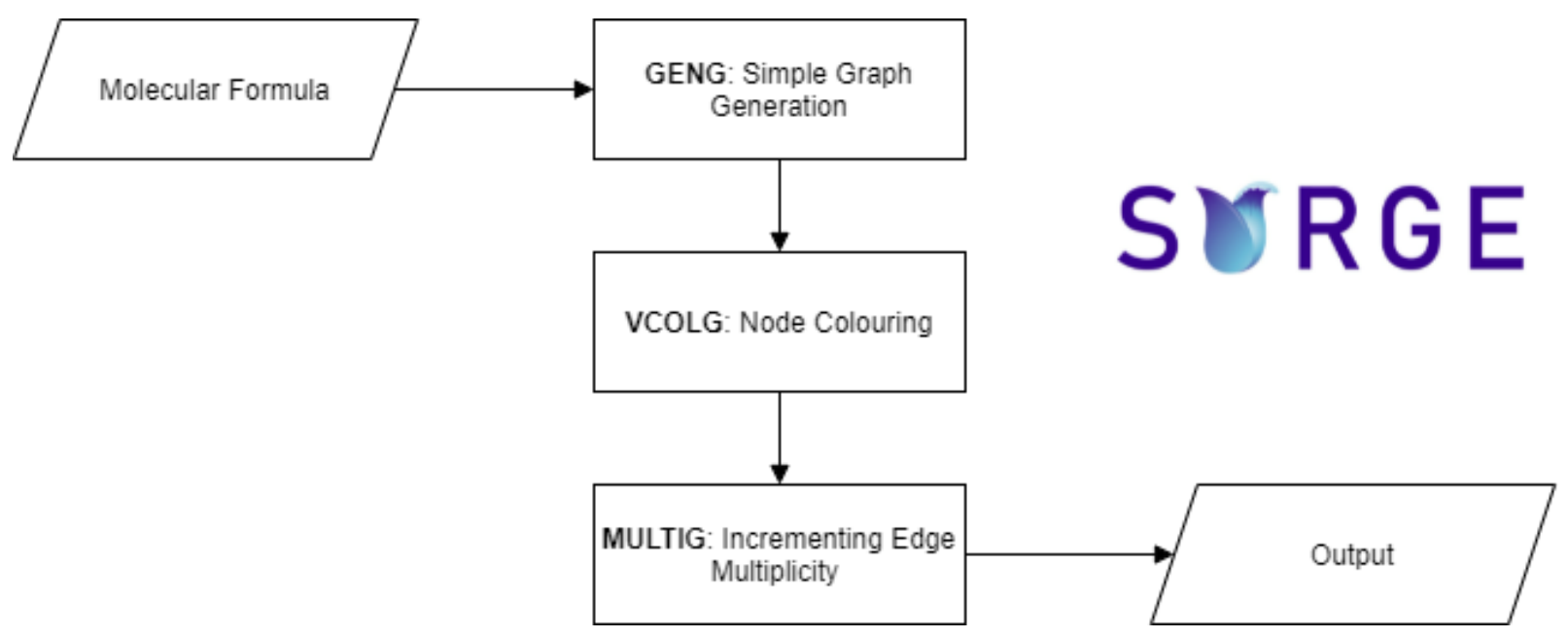

Figure 2: Surge flowchart.

An isomorphism between two graphs is a bijection between their vertex sets that maps edges onto edges. If the graphs have adornments, such as atom types for the vertices or bond multiplicities for the edges, then those adornments must be preserved by the mapping. If the two graphs are the same; i.e., the isomorphism is from a graph to itself, it is called an automorphism. The automorphisms form a group under the operation of function composition, called the automorphism group.

The meanings of isomorphism and automorphism are different for each of the three stages in our algorithm. Referring to Figure 1, at the first stage (which we call a simple graph) there are no vertex or edge adornments and all rotations and reflections, 10 in total, are automorphisms. 
When vertex adornments are added in the second stage, the atom type becomes significant so only the identity mapping and the reflection through the oxygen atom are automorphisms. In the final stage, edge adornments are added but in this example the automorphism group is not further reduced since the reflection through the oxygen atom preserves both atom type and bond multiplicity. Note how the automorphism groups in the second and third stages are subgroups of the automorphism groups in the previous stages.

\section{First stage}

Input to surge consists of a molecular formula such as $\mathrm{C}_{7} \mathrm{H}_{12} \mathrm{O}_{2} \mathrm{~S}$. Based on the element counts, in this case $\mathrm{C}=7, \mathrm{O}=2, \mathrm{~S}=1, \mathrm{H}=12$, the atom valencies are used to calculate the plausible range of the number of edges of a connected simple graph representing the topology of a molecule with this formula, with hydrogen atoms omitted. Then geng is called to generate all the connected simple graphs with those parameters, subject also to a maximum degree condition depending on the molecular formula [23]. Geng generates one graph from each isomorphism class and these are passed to the second stage as they are produced, without any need to store them [23]. In this example, there are 10 non-hydrogen atoms and the number of edges is in the range $9-11$.

\section{Second stage}

Given a simple graph $\mathrm{G}$ from the first stage, the second stage assigns elements to vertices in all distinct ways. The element counts must be correct, and we must have valence $\geq$ degree at each vertex. More onerously, we only want one member of each equivalence class of element assignment under the automorphism group of $\mathrm{G}$. We next explain how this is accomplished.

The vertices of $\mathrm{G}$ are arbitrarily numbered $1,2, \ldots, \mathrm{n}$. An element assignment can be represented as a list showing the element assigned to each vertex in order of vertex number. For example, a valid list might be $L=(C, C, C, S, O, C, C, C, O, C)$.

Automorphisms of $G$ have an action on lists that permutes their entries. Namely, for list $L$ and automorphism $\gamma$, the list $\gamma(L)$ assigns the same element to vertex $\gamma(v)$ as $L$ assigns to $v$, for each vertex v. Thus,

$$
L=(C, C, O, S, O, C, C, C, C, C) \text { and } \gamma=(123)(56) \text { imply } \gamma(L)=(O, C, C, S, C, O, C, C, C, C) \text {. }
$$

If $L$ is a list of elements and $\gamma$ is an automorphism, $L$ and $\gamma(L)$ give equivalent assignment of elements to the vertices of $\mathrm{G}$. Our task in this stage is to choose exactly one assignment from each equivalence class. Given a fixed ordering of the elements, for example $\mathrm{C}<\mathrm{O}<\mathrm{S}$, two lists can be compared lexicographically, for example

$$
(\mathrm{C}, \mathrm{C}, \mathrm{C}, \mathrm{S}, \mathrm{O}, \mathrm{C}, \mathrm{C}, \mathrm{C}, \mathrm{O}, \mathrm{C})<(\mathrm{C}, \mathrm{C}, \mathrm{O}, \mathrm{C}, \mathrm{S}, \mathrm{C}, \mathrm{C}, \mathrm{O}, \mathrm{C}, \mathrm{C})
$$

This enables us to define

$$
\operatorname{canon}(L)=\max \{\gamma(L) \mid \gamma \text { in } \operatorname{Aut}(G)\}
$$


the maximum list in the equivalence class of $L$. Note that canon $(L)=$ canon $\left(L^{\prime}\right)$ if $L$ and $L^{\prime}$ are equivalent, so there is a unique maximum list $L^{*}$ in the equivalence class and we can recognize it by the condition canon $\left(L^{*}\right)=L^{*}$. To put it another way, if $\gamma(L)>L$ for any automorphism $\gamma$ then $L$ $\neq \mathrm{L}^{*}$; otherwise $\mathrm{L}=\mathrm{L}^{*}$.

Now we describe the conceptual method for the second stage. For given G:

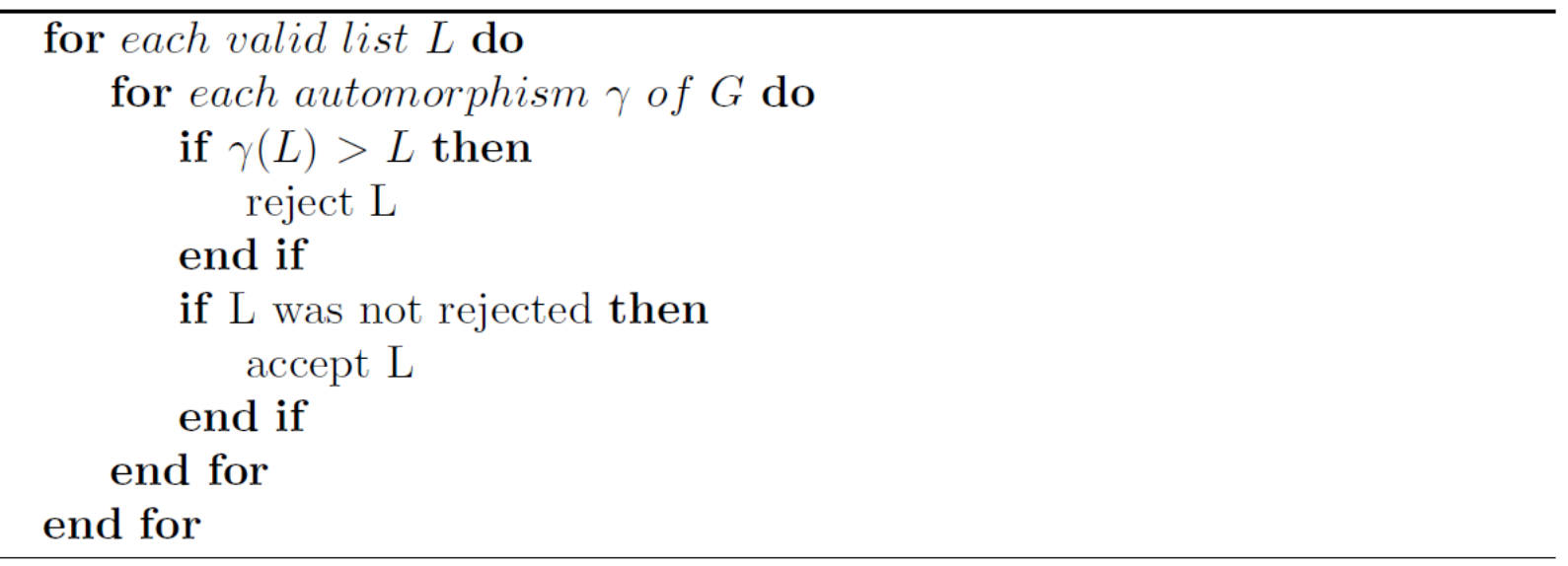

This algorithm is efficient if the automorphism group Aut $(G)$ is small, but that is not always the case. Therefore, we adopt a more complex approach. An automorphism of $\mathrm{G}$ is called minor if there are two leaves (vertices of degree 1) x,y with a common neighbour and the automorphism merely swaps $x$ and $y$; i.e. ( $x y)$. The minor subgroup $M \leq A u t(G)$ is the subgroup generated by all the minor automorphisms.
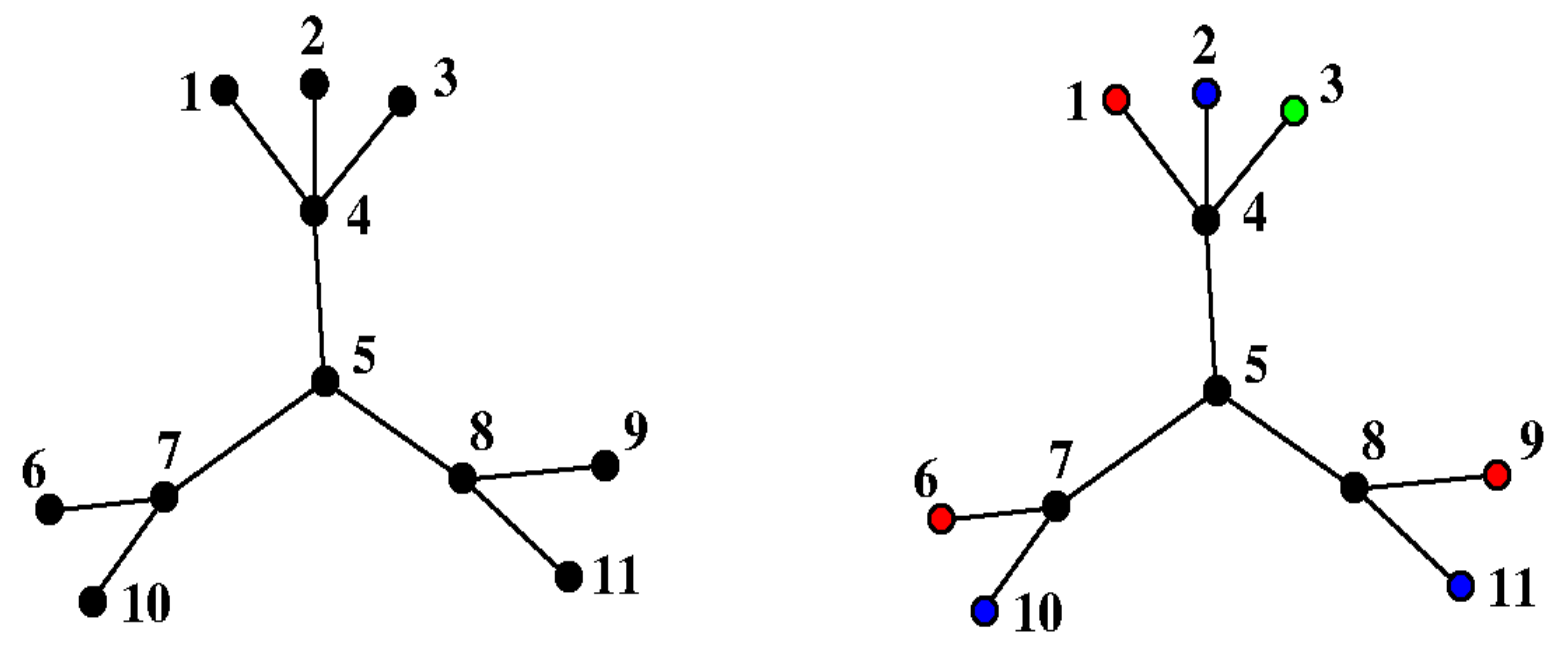

Figure 3. Two graphs with example flowers.

A flower is a maximal set of leaves with the same neighbour. In the left graph of Figure 3, the flowers are $\{1,2,3\},\{6,10\}$ and $\{9,11\}$. The minor subgroup $M$ consists of all automorphisms that 
preserve the flowers, such as $\left(\begin{array}{ll}1 & 2\end{array} 3\right)(911)$. The order of $M$ is $3 ! \times 2 ! \times 2 !=24$. In addition to $\mathrm{M}$, the automorphism group may contain automorphisms that do not preserve the flowers, such as $(6$ 11)(7 8)(9 10). To capture such automorphisms, we colour the graph as in the right side of Figure 3. Vertices not in flowers are coloured black. Within each flower, vertices are coloured red, blue, green, ... in order of vertex number, using a fixed list of colours that does not include black. Now let $\mathrm{N}$ be the group of automorphisms that respect the vertex colours. In the example, $\mathrm{N}$ has only the identity and $(69)(78)(1011)$.

An arbitrary automorphism of $\mathrm{G}$ can be obtained by first applying an element of $\mathrm{N}$ to capture how the flowers are mapped to each other, and then applying an element of $M$ to capture the movement of leaves within each flower. In both steps the choice is unique, so we have a factorization

$$
\operatorname{Aut}(\mathrm{G})=\mathrm{NM}=\{\gamma \delta \mid \gamma \text { in } \mathrm{N}, \delta \text { in } \mathrm{M}\} \text {. }
$$

(In the language of group theory, $\mathrm{M}$ is a normal subgroup and $\mathrm{N}$ is a complete set of coset representatives.) In the example, consider $(12)(611)(78)(910)$. It swaps the flowers $\{6,10\}$ and $\{9,11\}$ so we choose the element of $N$ which does that, namely $\gamma=(69)(78)(1011)$. Then we have to arrange the leaves within the flowers with an element of $M$, namely $\delta=(12)(610)(9$

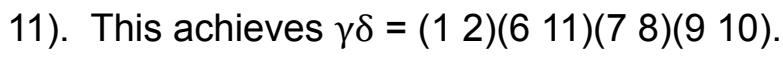

The main advantage of factoring $\operatorname{Aut}(\mathrm{G})=\mathrm{NM}$ is the following.

Theorem. For any list $L, L=$ canon( $(L)$ if and only if $L=\max \{\delta(L) \mid \delta$ in $M\}$ and $L=\max \{\gamma(L) \mid$ $\gamma$ in $N$ \}.

Proof. The "only if" direction is obvious since $M$ and $N$ are subsets of Aut(G). Suppose in the other direction that $L=\max \{\delta(L) \mid \delta$ in $M\}$ and $L=\max \{\gamma(L) \mid \gamma$ in $N\}$. From the factorization of Aut $(\mathrm{G})$ we know that $L^{*}=\delta(\gamma(L))$ for some $\gamma$ in $N$ and $\delta$ in $M$. Note that in both $L$ and $L^{*}$ the elements are in nonincreasing order within each flower, as they are maximized with respect to $\mathrm{M}$. Also recall that the automorphisms in $\mathrm{N}$ preserve the order of vertex numbers within the flowers, by virtue of the fact that we coloured the vertices in order of vertex number when we computed $N$. This means that we can take $\delta$ to be identity, and so $L^{*}=\gamma(L)$. This proves that $L^{*}$ $=\mathrm{L}$, since $\mathrm{L}=\max \{\gamma(\mathrm{L}) \mid \gamma$ in $\mathrm{N}\}$.

In order to implement the condition $L=\max \{\gamma(L) \mid \gamma$ in $M\}$, we don't need to compute $M$ explicitly. Instead, since $M$ is generated by transpositions, it suffices that within each flower the elements are in decreasing order relative to vertex number. Using the ordering of elements that we have chosen, in the example we just need to enforce the inequalities element(1) $\geq$ element(2) $\geq$ element(3), element(6) $\geq$ element(10) and element(9) $\geq$ element(11). The program recursively assigns elements to vertices in order of vertex number and enforces these inequalities as they become active rather than at the end.

To implement the condition $L=\max \{\gamma(L) \mid \gamma$ in $N\}$, we compute $N$ using nauty and test that $\gamma$ $(L) \leq L$ for each $\gamma$ in $N$. This is efficient in practice because $N$ is very small most of the time.

We can also partly enforce $\mathrm{N}$ by means of inequalities: since vertex 6 is the least vertex in a non-trivial orbit $\{6,9\}$ of $N$, we can assume element(6) $\geq$ element(9). This is not necessary but it gives a small time improvement. 


\section{Third stage}

After the assignment of elements to vertices is complete, the program moves to the next stage of selecting a bond multiplicity for each edge. This is the same type of problem as in the second stage. Instead of a list of elements for each vertex, we have a list of multiplicities for each edge. Instead of $\operatorname{Aut}(G)$, we use the subgroup of $\operatorname{Aut}(G)$ that preserves the element assignment. Otherwise $\mathrm{M}$ and $\mathrm{N}$ are defined as before. In the implementation, we don't use nauty to compute $\mathrm{N}$ but instead filter the $\mathrm{N}$ subgroup from the second stage, rejecting those automorphisms which don't preserve elements and converting the others to their action on the edges.

As an example, geng makes 534,493 unlabelled simple graphs in 1.3 seconds for Lysopine $\mathrm{C}_{9} \mathrm{H}_{18} \mathrm{~N}_{2} \mathrm{O}_{4}$. For these graphs, the second stage subgroup $\mathrm{N}$ is trivial $58 \%$ of the time and never larger than 72. Assignment of elements to vertices produces 3,012,069,151 vertex-labelled graphs in 90 seconds. The $\mathrm{N}$ subgroup for the third stage is trivial $98 \%$ of the time and never larger than 24. Finally, the assignment of bond multiplicities produces 5,979,199,394 completed molecules in an additional 100 seconds.

As demonstrated by our examples, surge can generate molecular structures very quickly, allowing for the inspection of extremely large sets of isomers. The generation speed is several times faster than even the fastest output format (SMILES). On the other hand, any particular application will likely have stronger restrictions on the structure than just a molecular formula. For example, some substructures may make the molecule unstable or give it chemical properties undesirable in the application. Or, experimental investigation of an unknown compound may have determined some features of the structure, so that only molecules with those features are of interest.

For these reasons, surge provides a number of filters to limit the output. The 3-stage generation method allows some of them to be implemented almost for free, and all of them are much more efficient than filtering the output through an external program. For example, restrictions on the number of short rings and the planarity of the molecule can be enforced at Stage 1. Surge also provides some "badlists" of forbidden substructures (many of them inspired by the corresponding feature of MOLGEN).

The open-source nature of surge allows for a more advanced feature. By writing small code snippets, the user can insert custom filters into any of the three stages, and also perform such tasks as adding extra elements and command-line options. Several worked examples are provided with the program.

\section{Results}

Surge is available under a liberal open-source License (Apache 2.0) on GitHub at https://structuregenerator.github.io as well as from https://users.cecs.anu.edu.au/ bdm/surge/.

The system can be built with the standard Unix Configure/Make scheme and the resulting stand-alone executable is then run from the command line. By default, surge generates all constitutional isomers of a given molecular formula. Surge can write output in either SDfile [24] 
or SMILES [25] format. SMILES output is produced very efficiently by constructing a template for each simple graph at the first stage, so that only atom types and bond multiplicity must be filled in before output.

We benchmarked surge with the set of molecular formulae given in Table 1. Since our motivation for developing structure generators is for the generation of large molecules, Table 1 consists of natural products, randomly selected from the natural products database COCONUT [20]. For the list of molecular formulae, surge outperformed MOLGEN by orders of magnitude (Figure 4) and MOLGEN terminated at a built-in limit of $2^{31}-1$ structures. Reported computation times were linearly extrapolated based on the MOLGEN timing for $2^{31}-1$ structures and the actual number of isomers reported by surge. Note that surge generates between 7 million and 22 million molecules per second for all of these examples.

Surge has a tiny memory footprint irrespective of the molecule size or the number of isomers. All of the examples in this paper run in at most 5 MB of RAM on Linux.

Table 1: Execution time (seconds) for selected MF of natural products on a compute-optimized c2-standard-4 Google cloud VM. Times for MOLGEN 5.0 were determined with the -noaromaticity flag to achieve comparability. Both MOLGEN and surge were instructed to generate but not to output structures.

\begin{tabular}{|l|l|l|l|l|l|}
\hline $\begin{array}{l}\text { Name of notable } \\
\text { isomer }\end{array}$ & $\begin{array}{l}\text { Molecular } \\
\text { Formula }\end{array}$ & Species & \#lsomers & $\begin{array}{l}\text { SURGE } \\
\text { time (s) }\end{array}$ & $\begin{array}{l}\text { MOLGEN } \\
\text { time (s) }\end{array}$ \\
\hline Bassianolone & $\mathrm{C}_{10} \mathrm{H}_{16} \mathrm{O}_{5}$ & $\begin{array}{l}\text { Beauveria } \\
\text { bassiana }\end{array}$ & 1092378303 & 69 & 5146 \\
\hline Pantothenate & $\mathrm{C}_{9} \mathrm{H}_{17} \mathrm{NO}_{5}$ & $\begin{array}{l}\text { Arabidopsis } \\
\text { thaliana }\end{array}$ & 1652346465 & 165 & 11122 \\
\hline Lysopine & $\mathrm{C}_{9} \mathrm{H}_{18} \mathrm{~N}_{2} \mathrm{O}_{4}$ & $\begin{array}{l}\text { Parthenocissus } \\
\text { tricuspidata }\end{array}$ & 5979199394 & 289 & 27250 \\
\hline Cribronic Acid & $\mathrm{C}_{6} \mathrm{H}_{11} \mathrm{NO}_{7} \mathrm{~S}$ & $\begin{array}{l}\text { Cribrochalina } \\
\text { olemda }\end{array}$ & 2375932807 & 323 & 13445 \\
\hline Antibiotic CV-1 & $\mathrm{C}_{7} \mathrm{H}_{14} \mathrm{~N}_{2} \mathrm{O}_{6}$ & $\begin{array}{l}\text { Streptomyces } \\
\text { CO-1 }\end{array}$ & 4193416397 & 448 & 24030 \\
\hline Thr-Thr & $\mathrm{C}_{8} \mathrm{H}_{16} \mathrm{~N}_{2} \mathrm{O}_{5}$ & $\begin{array}{l}\text { Trypanosoma } \\
\text { brucei }\end{array}$ & 5955022220 & 575 & 37103 \\
\hline $\begin{array}{l}\text { O-Succinyl-L-Ho } \\
\text { moserine }\end{array}$ & $\mathrm{C}_{8} \mathrm{H}_{13} \mathrm{NO}_{6}$ & $\begin{array}{l}\text { Escherichia coli } \\
\text { K12 }\end{array}$ & 5639328954 & 629 & 746 \\
\hline Etrogol & $\mathrm{C}_{13} \mathrm{H}_{18} \mathrm{O}_{2}$ & Stachylidium & 6316260274 & 1187 & 44395 \\
\hline Indoleacetamide & $\mathrm{C}_{10} \mathrm{H}_{10} \mathrm{~N}_{2} \mathrm{O}$ & $\begin{array}{l}\text { Pseudomonas } \\
\text { savastanoi }\end{array}$ & 13290477420 & 5910 \\
\hline
\end{tabular}




\begin{tabular}{|c|c|c|c|c|c|}
\hline Colletotricole A & $\mathrm{C}_{9} \mathrm{H}_{13} \mathrm{NO}_{3} \mathrm{~S}$ & $\begin{array}{l}\text { Colletotrichum } \\
\text { gloeosporioides } \\
\text { A12 }\end{array}$ & 20902484656 & 1765 & 88151 \\
\hline Nigerapyrone E & $\mathrm{C}_{11} \mathrm{H}_{12} \mathrm{O}_{4}$ & $\begin{array}{l}\text { Aspergillusniger } \\
M A-132\end{array}$ & 31627481929 & 2179 & 181725 \\
\hline Siastatin B & $\mathrm{C}_{8} \mathrm{H}_{14} \mathrm{~N}_{2} \mathrm{O}_{5}$ & $\begin{array}{l}\text { Streptomyces } \\
\text { verticillus var. } \\
\text { quintum }\end{array}$ & 27692853176 & 2628 & 183167 \\
\hline $\begin{array}{l}\text { P-Hydroxyhippuri } \\
\text { c Acid }\end{array}$ & $\mathrm{C}_{9} \mathrm{H}_{9} \mathrm{NO}_{4}$ & Homo sapiens & 21964168804 & 2731 & 121362 \\
\hline $\begin{array}{l}\text { Deacetyldemethyl } \\
\text { anisomycin }\end{array}$ & $\mathrm{C}_{11} \mathrm{H}_{15} \mathrm{NO}_{3}$ & $\begin{array}{l}\text { Streptomyces sp. } \\
\text { strain SA3097 }\end{array}$ & 95541477841 & 4229 & 580772 \\
\hline $\begin{array}{l}\text { Isoleucylisoleucyl } \\
\text { Anhydride }\end{array}$ & $\mathrm{C}_{12} \mathrm{H}_{22} \mathrm{~N}_{2} \mathrm{O}_{2}$ & $\begin{array}{l}\text { Cordyceps } \\
\text { bassiana }\end{array}$ & 59576199503 & 4782 & 516950 \\
\hline Hydantocidin & $\mathrm{C}_{7} \mathrm{H}_{10} \mathrm{~N}_{2} \mathrm{O}_{6}$ & $\begin{array}{l}\text { Streptomyces } \\
\text { hygroscopicus }\end{array}$ & 40946033849 & 5238 & 262323 \\
\hline Aerugine & $\mathrm{C}_{10} \mathrm{H}_{11} \mathrm{NO}_{2} \mathrm{~S}$ & $\begin{array}{l}\text { Pseudomonas } \\
\text { aeruginosa }\end{array}$ & 93330898027 & 8124 & 533440 \\
\hline $\begin{array}{l}\text { Flavensomycinoic } \\
\text { Acid }\end{array}$ & $\mathrm{C}_{9} \mathrm{H}_{9} \mathrm{NO}_{5}$ & $N / A$ & 113165341837 & 8870 & 793389 \\
\hline $\begin{array}{l}\text { Dopamine } \\
\text { 4-O-Sulfate }\end{array}$ & $\mathrm{C}_{8} \mathrm{H}_{11} \mathrm{NO}_{5} \mathrm{~S}$ & Homo sapiens & 89694168554 & 9880 & 606333 \\
\hline Pestalactam C & $\mathrm{C}_{10} \mathrm{H}_{10} \mathrm{CINO}_{3}$ & pestalotiopsis sp. & 232824605597 & 14830 & 1700022 \\
\hline Glugaba & $\mathrm{C}_{9} \mathrm{H}_{16} \mathrm{~N}_{2} \mathrm{O}_{5}$ & Escherichia coli & 176162377006 & 16265 & 1315301 \\
\hline Shihunine & $\mathrm{C}_{12} \mathrm{H}_{13} \mathrm{NO}_{2}$ & $\begin{array}{l}\text { Dendrobium } \\
\text { loddigesii }\end{array}$ & 427207647324 & 19769 & 2504164 \\
\hline Gostatin & $\mathrm{C}_{8} \mathrm{H}_{10} \mathrm{~N}_{2} \mathrm{O}_{5}$ & sumanensis & 187389585693 & 21781 & 1422863 \\
\hline Elaiomycin & $\mathrm{C}_{13} \mathrm{H}_{26} \mathrm{~N}_{2} \mathrm{O}_{3}$ & $N / A$ & 303023674167 & 29288 & 2729280 \\
\hline Oryzoxymycin & $\mathrm{C}_{10} \mathrm{H}_{13} \mathrm{NO}_{5}$ & $\begin{array}{l}\text { Streptomyces } \\
\text { venezuelae var. } \\
\text { oryzoxymyceticus }\end{array}$ & 552024644350 & 54372 & 6325646 \\
\hline Gammaglucys & $\mathrm{C}_{8} \mathrm{H}_{14} \mathrm{~N}_{2} \mathrm{O}_{5} \mathrm{~S}$ & Mus musculus & 699785343381 & 69844 & 4989287 \\
\hline Phyllurine & $\mathrm{C}_{10} \mathrm{H}_{10} \mathrm{~N}_{2} \mathrm{O}_{3}$ & $\begin{array}{l}\text { Phyllanthus } \\
\text { urinaria }\end{array}$ & 1511861775412 & 83186 & 8292585 \\
\hline
\end{tabular}




\begin{tabular}{|l|l|l|l|l|l|}
\hline Vanilloylglycine & $\mathrm{C}_{10} \mathrm{H}_{11} \mathrm{NO}_{5}$ & Homo sapiens & 1182104108010 & 133136 & 21426660 \\
\hline Deoxyuridine & $\mathrm{C}_{9} \mathrm{H}_{12} \mathrm{~N}_{2} \mathrm{O}_{5}$ & $\begin{array}{l}\text { Phakellia } \\
\text { mauritiana }\end{array}$ & 1795817811706 & 180727 & 13983652 \\
\hline Sulphostin & $\mathrm{C}_{5} \mathrm{H}_{13} \mathrm{~N}_{4} \mathrm{O}_{5} \mathrm{PS}$ & N/A & 2029911211739 & 226830 & 11893149 \\
\hline
\end{tabular}

\section{Surge vs Molgen Benchmark}

- SURGE - MOLGEN - Isomers

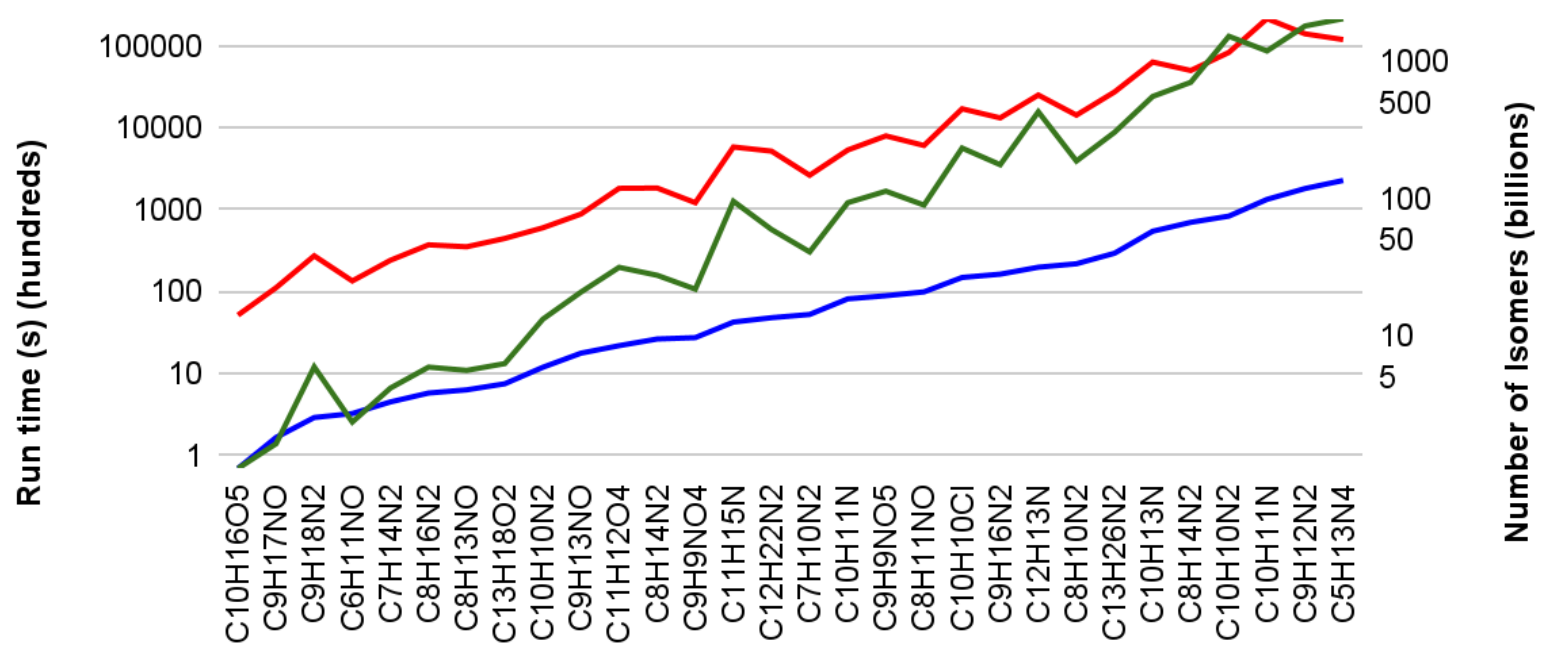

Molecular Formula

Figure 4: Comparison of the run times of surge v1.0 vs MOLGEN 5.0 for long-running molecular formulae from selected natural products, plotted on a logarithmic time scale. In the majority of cases, MOLGEN terminated at a built-in limit of $2^{31}-1$ structures. Reported computation times were linearly extrapolated based on the MOLGEN timing for $2^{31}-1$ structures and the actual number of isomers reported by surge.

For randomly selected 10 molecular formulae, 4 options of surge were tested and results are given in Table 2. These options are

-p0:1 At most one cycle of length 5

$-\mathrm{P} \quad$ The molecule is planar

-B5 No atom has two double bonds and otherwise only hydrogen neighbours

-B9 No atom lies on more than one cycle of length 3 or 4 
Table 2: Execution time (seconds) for selected MF of natural products on a compute-optimized c2-standard-4 Google cloud VM. Surge was run with its options and instructed to generate but not to output structures.

\begin{tabular}{|c|c|c|c|c|c|c|c|c|}
\hline \multirow{2}{*}{$\begin{array}{l}\text { Molecular } \\
\text { Formula }\end{array}$} & \multicolumn{2}{|c|}{$-p 0: 1$} & \multicolumn{2}{|l|}{$-P$} & \multicolumn{2}{|l|}{ - B5 } & \multicolumn{2}{|l|}{ - B9 } \\
\hline & \#Iso & Time & \#Iso & Time & \#Iso & Time & \#lso & Time \\
\hline $\mathrm{C}_{11} \mathrm{H}_{19} \mathrm{~N}_{3} \mathrm{O}$ & $\begin{array}{l}58175540 \\
999\end{array}$ & 3746 & 72486967073 & 5046 & 69648876936 & 4978 & 51275365737 & 3048 \\
\hline $\begin{array}{l}\mathrm{C}_{11} \mathrm{H}_{18} \mathrm{~N}_{2} \mathrm{O} \\
2\end{array}$ & $\begin{array}{l}539257253 \\
34\end{array}$ & 3648 & 67177819545 & 4914 & 64367528959 & 4838 & 47278714772 & 2946 \\
\hline $\mathrm{C}_{11} \mathrm{H}_{15} \mathrm{NO}_{3}$ & $\begin{array}{l}64661412 \\
269\end{array}$ & 4759 & 94361334994 & 7682 & 89131725467 & 7512 & 54627135057 & 3595 \\
\hline $\mathrm{C}_{9} \mathrm{H}_{18} \mathrm{~N}_{2} \mathrm{O}_{4}$ & $\begin{array}{l}58104096 \\
23\end{array}$ & 519 & 5979199394 & 541 & 5918503858 & 538 & 5583717596 & 484 \\
\hline $\mathrm{C}_{11} \mathrm{H}_{12} \mathrm{O}_{4}$ & $\begin{array}{l}172164980 \\
94\end{array}$ & 1894 & 30438650047 & 4485 & 28660902856 & 3777 & 14044693099 & 1256 \\
\hline $\mathrm{C}_{10} \mathrm{H}_{16} \mathrm{O}_{5}$ & $\begin{array}{l}98927353 \\
0\end{array}$ & 107 & 1092378303 & 122 & 1060206152 & 122 & 895109814 & 88 \\
\hline $\mathrm{C}_{13} \mathrm{H}_{20} \mathrm{O}_{2}$ & $\begin{array}{l}12114813 \\
07\end{array}$ & 147 & 1514909702 & 203 & 1443691541 & 197 & 1038843543 & 101 \\
\hline $\mathrm{C}_{8} \mathrm{H}_{11} \mathrm{NO}_{6}$ & $\begin{array}{l}12795251 \\
232\end{array}$ & 1511 & 15771433061 & 1953 & 15035794185 & 1942 & 11169581507 & 1217 \\
\hline $\mathrm{C}_{9} \mathrm{H}_{9} \mathrm{NO}_{5}$ & $\begin{array}{l}624711257 \\
88\end{array}$ & 8244 & 109135601623 & 16008 & 102826808386 & 15645 & 51607646947 & 6062 \\
\hline $\mathrm{C}_{12} \mathrm{H}_{13} \mathrm{NO}_{2}$ & $\begin{array}{l}17727444 \\
6997\end{array}$ & 13639 & 382246449331 & 34476 & 381333513411 & 34285 & 147423365942 & 9700 \\
\hline
\end{tabular}

\section{Limitations}

Release 1.0 of surge does not perform a Hückel aromaticity test and therefore generates duplicate structures for Kekulé versions of aromatic rings that are graph-theoretically different. Benchmarking against MOLGEN 5.0 was therefore performed with the -noaromaticity switch of MOLGEN. 


\section{Conclusion}

We have presented surge, a structure generator for constitutional isomers based on the canonical generation path method. To the best of our knowledge, surge is the fastest chemical structure generator available. A number of badlist options are available to avoid the generation of potentially unlikely structures. Current limitations include the lack of an aromaticity detection. Surge is hosted as an open-source package on GitHub, inviting the scientific community to use and extend it. Surge offers a plug-in mechanism for community-driven extensions. Plugins can hook into the various stages of the surge generation process, thereby offering efficient means to prune the generation tree.

\section{Availability and Requirements}

- Project name: surge

- Project home page: https://structuregenerator.github.io

- Operating system(s): Platform independent

- Programming language: $\mathrm{C}$

- License: Apache 2.0

\section{Competing Interests}

All authors declare no competing interests.

\section{Funding}

MAY and CS acknowledge funding by the Carl-Zeiss-Foundation.

\section{Acknowledgements}

\section{Author contributions}

BDM wrote the code and developed the underlying nauty package. BDM, CS and MAY conceived the project. BDM and CS guided the development. MAY contributed to the conceptual development and performed the evaluation and testing. All authors wrote, read and approved the manuscript. 


\section{Author information}

\section{Affiliations}

School of Computing, Australian National University, ACT 2601, Australia

Brendan D. McKay

Institute for Inorganic and Analytical Chemistry, Friedrich-Schiller-University, Jena, Germany Mehmet Aziz Yirik \& Christoph Steinbeck

\section{References}

1. Elyashberg M, Argyropoulos D. Computer Assisted Structure Elucidation (CASE): Current and future perspectives. Magn Reson Chem [Internet]. Wiley; 2020; Available from: https://onlinelibrary.wiley.com/doi/10.1002/mrc.5115

2. Miyao T, Kaneko H, Funatsu K. Ring system-based chemical graph generation for de novo molecular design. J Comput Aided Mol Des. 2016;30:425-46.

3. Saldívar-González FI, Huerta-García CS, Medina-Franco JL. Chemoinformatics-based enumeration of chemical libraries: a tutorial. J Cheminform. 2020;12:64.

4. Blum LC, Reymond J-L. 970 Million Druglike Small Molecules for Virtual Screening in the Chemical Universe Database GDB-13. J Am Chem Soc. American Chemical Society; 2009;131:8732-3.

5. Lindsay RK, Buchanan BG, Feigenbaum EA, Lederberg J. DENDRAL: A case study of the first expert system for scientific hypothesis formation. Artif Intell. 1993;61:209-61.

6. Gulyaeva KA, Artemieva IL. The ontological approach in organic chemistry intelligent system development. Advances in Intelligent Systems and Computing. Singapore: Springer Singapore; 2020. p. 69-78.

7. Badertscher M, Korytko A, Schulz KP, Madison M, Munk ME, Portmann P, et al. Assemble 2.0: a structure generator. Chemometrics Intellig Lab Syst. 2000;51:73-9.

8. Holt DF, Eick B, O’Brien EA. Handbook of Computational Group Theory. CRC Press; 2005.

9. Kreher DL, Stinson DR. Combinatorial algorithms: generation, enumeration, and search. CRC press; 2020.

10. Serov VV, Elyashberg ME, Gribov LA. Mathematical synthesis and analysis of molecular structures. J Mol Struct. 1976;31:381-97.

11. Molchanova MS, Shcherbukhin VV, Zefirov NS. Computer Generation of Molecular Structures by the SMOG Program. J Chem Inf Comput Sci. 1996;36:888-99.

12. Yirik MA, Steinbeck C. Chemical graph generators. PLoS Comput Biol. 2021;17:e1008504. 
13. Junker J. Theoretical NMR correlations based Structure Discussion. J Cheminform. 2011;3:27.

14. Nuzillard J-M, Georges M. Logic for structure determination. Tetrahedron. 1991;47:3655-64.

15. Gugisch R, Kerber A, Kohnert A, Laue R, Meringer M, Rücker C, et al. MOLGEN 5.0, a Molecular Structure Generator in Advances in Mathematical Chemistry. Advances in Mathematical Chemistry; Basak, SC, Restrepo, G, Villaveces, JL, Eds.

16. Grund R, Kerber A, Laue R. Construction of discrete structures, especially isomers. Discrete Appl Math. 1996;67:115-26.

17. Grüner T, Laue R, Meringer M. Algorithms for group actions: homomorphism principle and orderly generation applied to graphs. DIMACS Ser Discrete Math Theoret Comput Sci. 1997;28:113-22.

18. Yirik MA, Sorokina M, Steinbeck C. MAYGEN: an open-source chemical structure generator for constitutional isomers based on the orderly generation principle [Internet]. Journal of Cheminformatics. 2021. Available from: http://dx.doi.org/10.1186/s13321-021-00529-9

19. Ruddigkeit L, van Deursen R, Blum LC, Reymond J-L. Enumeration of 166 billion organic small molecules in the chemical universe database GDB-17. J Chem Inf Model. 2012;52:2864-75.

20. Sorokina M, Merseburger P, Rajan K, Yirik MA, Steinbeck C. COCONUT online: Collection of Open Natural Products database. J Cheminform. 2021;13:2.

21. McKay BD, Piperno A. Practical graph isomorphism, II. J Symbolic Comput. 2014;60:94-112.

22. McKay B, Piperno A. nauty and Traces User's Guide [Internet]. 2019 Sep. Available from: https://pallini.di.uniroma1.it/Guide.html

23. McKay BD. Isomorph-Free Exhaustive Generation. J Algorithms. 1998;26:306-24.

24. CTFILE FORMATS BIOVIA DATABASES 2016 [Internet]. 2016. Available from: https://help.accelrysonline.com/ulm/onelab/1.0/content/ulm_pdfs/direct/reference/ctfileformats20 16.pdf

25. Weininger D. SMILES, a Chemical Language and Information System. 1. Introduction to Methodology and Encoding Rules. J Chem Inf Comput Sci. ACS AMERICAN CHEMICAL SOCIETY; 1988;28:31-6. 